\title{
Article
}

\section{'Getting Back Into the Swing of Things': A Qualitative Study Into Barriers and Facilitators to Golf Participation for Stroke Survivors}

Fry, John, Mcmahon, Naoimh, Hall, Philip J., Barron, David J, Davies, Thomas, Yiannaki, Chris and Watkins, Caroline Leigh

Available at http://clok.uclan.ac.uk/20318/

Fry, John, Mcmahon, Naoimh ORCID: 0000-0001-6319-2263, Hall, Philip J., Barron, David J, Davies, Thomas, Yiannaki, Chris and Watkins, Caroline Leigh ORCID: 0000-0002-9403-3772 (2017) 'Getting Back Into the Swing of Things': A Qualitative Study Into Barriers and Facilitators to Golf Participation for Stroke Survivors. International Journal of Golf Science, 6 (1). pp. 20-34. ISSN 2168-7595

It is advisable to refer to the publisher's version if you intend to cite from the work. http://dx.doi.org/10.1123/ijgs.2017-0011

For more information about UCLan's research in this area go to http://www.uclan.ac.uk/researchgroups/ and search for < name of research Group>.

For information about Research generally at UCLan please go to http://www.uclan.ac.uk/research/

All outputs in CLoK are protected by Intellectual Property Rights law, including Copyright law. Copyright, IPR and Moral Rights for the works on this site are retained by the individual authors and/or other copyright owners. Terms and conditions for use of this material are defined in the policies page. 
A Qualitative Study into Barriers and Facilitators to Golf Participation for Stroke Survivors

John Fry $^{1}$, Naoimh E. McMahon ${ }^{2}$, Philip J. Hall ${ }^{1}$, David J. Barron ${ }^{1}$, Thomas Davies $^{1}$, Chris Yiannaki ${ }^{1}, \&$ Caroline Watkins ${ }^{2}$

12

${ }^{1}$ Centre for Research in Sport Performance, Myerscough College

${ }^{2}$ Faculty of Health and Wellbeing, University of Central Lancashire, Preston, PR1 2HE

17

\section{Corresponding author:}

21 John Fry, Lead Researcher for Sport, Centre for Research in Sport Performance / International 22 Institute for Golf Education, Myerscough College, St Michael's Rd, Bilsborrow, Preston, PR3 23 ORY, 01995642222.

24 Email: jfry@ myerscough.ac.uk 


\section{Abstract}

5

6 This paper draws on interviews with four stroke survivors, who participated in a five week

7 'Get-into-Golf' program and four coaches with experiences of delivering disability golf

8 sessions, to examine the barriers and facilitators to golf participation. Findings indicate a

9 positive response from participants, who referred to the social and physical benefits of the

10 programme that was perceived to promote independence. The results also highlight that

11 considerations in regards to format, equipment, cost, access and overall awareness should be

12 borne in mind for golf programmes amongst people with disabilities. Golf clubs could employ

13 this framework to inform provision in order to facilitate the participation of people with

14 physical limitations. It is argued that opportunities to promote golf as a lifelong physical

15 activity among people with disabilities may be missed in clubs where personnel are unsure of

16 the barriers and facilitators to participation outlined here.

\section{Keywords}

20 Golf, health and well-being, stroke, disability, leisure, participation 
1 'Getting back into the Swing of Things': A Qualitative Study into Barriers and Facilitators to

2 Golf Participation for Stroke Survivors

3

4

5 disability in industrialized countries (Johnston, Mendis, \& Mathers, 2009). After the age of 45

6 around a quarter of all people experience a stroke, a figure which is increasing because of

7 modern lifestyle factors including: physical inactivity, increasing diabetes, and obesity

8 disorders (Pollock et al., 2014; Schachten, \& Petra, 2015). The most frequent form of stroke is

9 ischemic, which occurs when blood supply to certain parts of the brain is cut off, usually though a clot, and can cause a number of neuropsychological and motor deficits. These can reduce people's cognitive and emotional functions, and thus affect the way that the body works and how people think (Chen, Leys, \& Esquenazi, 2013). There are, of course, individual differences and levels of severity, but common issues post stroke include memory problems, slow thinking, speech, vision, and mobility impairments (Sacco et al., 2006). After experiencing a stroke, people's lives change significantly. They can often no longer take part in activities which they previously could, and have particular difficulties taking part in something new (Mayo et al., 2015; Nicholson et al., 2013). This further compounds and impacts on their individual health and well-being, where stroke survivors often find it difficult to undertake day-to-day tasks and it has been reported that many do not like to ask for additional help (Mayo et al., 2015). The impacts of stroke are particularly concerning as the demographic of stroke survivors consists of a high number of older adults of retirement age (Korner-Bitensky, Desrosiers, \& Rochette, 2008), who may be particularly vulnerable to social isolation after a stroke. Additionally, one in three stroke survivors experience post-stroke depression (Hackett \& Pickles, 2014) and greater engagement in valued activities has been shown to be positively associated with 
1 improvement in emotional well-being after stroke (Egan, Davis, Dubouloz, Kessler, \& Kubina, 2 2014).

One of the most attractive aspects of golf is that there are few age or skill limits to 5 participation, which, in principle, makes it one of the most/more accessible sports. Indeed, the popularity of golf amongst individuals with disabilities is increasing, and an associated rise in

7 the amount of disability golf societies and unions available to support golfers that require adapted opportunities for participation (Stoter et al., 2017). Golf is, in origin, an accessible competitive sport for people with impairments given the adaptations and modifications available, combined with the golf handicap system, thus helping to facilitate an environment where golfers of all abilities can compete equitably (Stoter et al., 2017). In order to further accommodate golfers with disabilities, The Royal and Ancient Golf Club of St. Andrews (R\&A) and the United States Golf Association (USGA) have produced a modification to the rules of golf for golfers who require provisions for adapted participation (Schachten \& Petra, 2015).

Additional benefits of golf participation after stroke may include improvements in motor control, visual imagery ability and increased opportunity to engage in physical activity (Schachten \& Petra, 2015; Shatil et al., 2005). Various studies have indicated that taking part in physical activity, for example, can help aid recovery and reduce the likelihood of recurrent strokes (Marzolini et al., 2013; Sacco et al., 2006; Saunders et al., 2016; van de Port et al., 2012). Indeed there has been a rise in the number of initiatives aiming to improve health and well-being using sport. Examples in golf include, "Saving Strokes" which has been described as a "golf therapy program" ran by American Heart/Stroke Association (AHSA, 2016) and the "Get-into-Golf" programme for stroke survivors ran by England Golf and the Stroke Association UK (England Golf, 2016). Despite this, low levels of physical activity still persist 
1 among stroke survivors due to barriers such as: concerns around balance and falling; lack of

2 services, transport, and support; perceptions about physical activity prerequisites (Nicholson et al., 2013; Rand et al., 2010; Simpson \& Eng, 2011). Furthermore, studies around exercise and stroke tend to focus on the physical benefits and there are few studies on emotional well-being in stroke patients (Schachten, \& Petra, 2015). Despite the potential of golf, participation by disability groups remains low, and out of those who do play there is little transition into regular participation (Kenny, 2015; Piggott, Leslie, \& Poller, 2011; Sandt, Flynn, \& Turner, 2014). The purpose of this paper, therefore, was twofold. Firstly, to assess the barriers and facilitators to golf participation amongst people who have experienced a disability from a stroke. Secondly, we will suggest a preliminary framework in which golf clubs could encourage more involvement amongst people who have physical limitations.

\section{Methods}

\section{$\underline{\text { Study design }}$}

The research design used is a 'case study' approach involving an in depth analysis of stroke survivors' experiences of golf. Case studies are typically concerned with the particular complexities of a specific case in order to examine contextual conditions that may be pertinent to particular groups of people by exploring social phenomena in their 'real-life' context (Bryman, 2015; Jones, 2014). Semi-structured interviews and focus groups were, therefore, selected given the interpretive data they produce and its suitability to the case study approach adopted. Semi-structured interviews were undertaken with four stroke survivors who had completed a five week get-into-golf programme (age range $=52-68, \mathrm{M}=59, \mathrm{SD}=7$ ), four sports coaches with experience delivering golf sessions to people with disabilities (age range $=34-37, \mathrm{M}=35, \mathrm{SD}=1.8$ ), and a focus group conducted with two employees from the Stroke 
1 Association involved in hosting golf initiatives for people with physical limitations (age range

$2=29-59, \mathrm{M}=44, \mathrm{SD}=21)$.

3

$4 \quad$ Participants

5

6 Association, who had organised a five week 'Get-into-Golf' programme for stroke survivors.

7 Participants had originally been referred from a stroke unit in the North West, to the Stroke

8 Association for additional support and rehabilitation following discharge. The 'Get-into-Golf'

9 programme is a national governing body initiative to encourage beginners to take up golf, run

10 by England Golf delivered locally by golf clubs and PGA professionals. The specific programme under analysis here was organised exclusively for stroke survivors, and lasted for five weeks at a golf club in the North West. The sessions were funded using a Stroke Association development grant but required a small contribution from each participant. The coaches and organisers were recruited from those involved in delivering the initiative.

\section{$\underline{\text { Data collection }}$}

Interviews and focus groups took place in a private area of a golf club convenient to the participant, were recorded and transcribed verbatim. Two semi-structured interview guides (one for the stroke survivors and another for the coaches) were adopted primarily so participants could elaborate without the rigidity of structured questions, with questions centring on themes including: experiences of the 'Get-into-Golf' programme, reasons for attending, and potential barriers to participation. This methodology allowed us to investigate the ways in which stroke survivors, professional coaches, and event organisers, viewed the barriers to golf from their own perspective (Bryman, 2015; Rubin, 2011). This strategy also helped the researchers to remain open-minded and follow the direction of data, which was guided by the 
1 qualitative findings as they unfolded. Participants could explain the 'reality' of their

2 experiences, allowing for an emotional response (Bryman, 2015; Veal \& Darcy, 2014).

3

\section{$4 \quad$ Data analysis}

5

\section{Ethical approval}

NVivo 9 was utilized to code interview transcripts and organize themes. Theoretical categories were developed to a point where no new ideas or themes were being generated that challenged or refined the explanations already uncovered (Guest, Bunce, \& Johnson, 2006; Jones, 2014; Veal \& Darcy, 2014). Comparing responses between interviewees allowed for the findings to be corroborated between participants and thus enhance the overall validity of the study. Saturation point was determined by the quality of the analysis that was constructed in terms of its depth and ability to explain the barriers and facilitators to playing golf.

The project was granted ethical clearance by Myerscough College's Faculty Research Ethics Committee (FREC). Participants were given a guarantee that all data will remain confidential. As a result, a number of pseudonyms have been used (see table 1). All participants were informed that the researcher team will be the only people to have access to the data. All sensitive files were password protected and kept on a password secured computer ensuring no unauthorised access. An important ethical consideration for this study concerned any potential harm to interviewees. It was possible participants could be vulnerable to stress given they were discussing the effects of a stroke on their lives. As such, it was important to closely analyse all conversations in order to guard against progressing down routes that may have distressed participants. The chance of adverse effects was significantly reduced given all participants were clearly briefed on what the study entailed, given an opportunity to scrutinise the participant information sheet and required to sign the consent form indicating they were prepared to take 
1 part. Each participant was informed as to the nature of the study and the use of the data supplied

2 before interviews commenced. Participants were given the assurance that they were able to contact the researcher at any time, from the details on the participant information sheet, thus

4 5

6

7 ensuring their right to withdraw at any stage during or after the interview.

\section{Results}

The aims of this paper were to, firstly, assess the barriers and facilitators to golf participation amongst people who have experienced a disability from a stroke, and, secondly, suggest a preliminary framework in which golf clubs could encourage more involvement amongst people who have physical limitations. The findings are presented in two main themes which encompass a number of related subthemes. Firstly, we will assess participants' perceptions of the 'get-into-golf' programme, by referring to the social elements of the initiative, impacts on physical health, and perceived levels of independence. We will then analyse the provisions required to support people with physical limitations in the golf environment, including organisation of spaces, awareness of disability related issues, and use of adaptive equipment. The findings will be discussed in light of relevant literature as we go.

\section{Characteristics of participants}

Participants were invited to take part in the golf initiative, virtually all were experiencing golf for the first time and none were members of clubs.

Table 1 Characteristics of participants

Participant Pseudonym

\begin{tabular}{cccl}
\hline Andrew & 68 & Male & Stroke survivor \\
\hline Brian & 62 & Male & Stroke survivor \\
\hline Catherine & 52 & Female & Stroke survivor \\
\hline Deborah & 57 & Female & Stroke survivor \\
\hline
\end{tabular}




\begin{tabular}{cccc}
\hline Edward & 37 & Male & PGA Golf Professional \\
\hline Fred & 33 & Male & Sports Development Officer and Coach \\
\hline Grace & 34 & Female & PGA Golf Professional \\
\hline Harry & 36 & Male & PGA Golf Professional \\
\hline Irene & 59 & Female & Stroke Association Employee \\
\hline Jackie & 29 & Female & Stroke Association Employee \\
\hline
\end{tabular}

1

2 Perceptions and experiences of the 'Get-Into-Golf' Initiative

3 There was a positive response from participants regarding their experiences of the get-into-golf

4 programme. For example, Andrew commented that "when I came here with this lot ... it was

5 nice. And then next week we come back again and then again, it's still good". Similarly, both

6 Brian and Deborah commented that "it was good, good yeah, very enjoyable, yeah" and "I like

7 it all, I like it a lot. Erm, I really do like it" respectively. When probed as to why the participants

8 felt that way, many referred to the key part that 'social elements' of the initiative played. For

9 example, this included meeting new people who were in a similar situation to themselves, and the value of talking with such individuals. It was these reasons which mean that good quality on site (but off course) social areas, such as a restaurant, cafe, or bar, were cited as being very important. Indeed Irene from the focus group commented that it was important to "keep activities close to club house". This is supported by the coaches' views, such as Edward, who commented that often people who do not take part in golf "see it as an individual sport and not seeing the social opportunities and interaction which comes with it". Similarly, Harry argues that the "social aspect is often really overlooked, somebody with a disability who wants to make friends, or just get out of the house and interact with people, then golf is a great way of doing that". It appears, therefore, that that promoting the social element of golf is a key aspect of participation. 

centred on perceptions of independence. Loss of independence is significant factor that impacts on health and wellbeing with many stroke survivors', who have experienced a life changing event (Pollock et al., 2014). In the focus group, Jackie heighted that a key part of planning was to help ensure the "sessions were very welcoming and encouraged being independent". This sentiment was supported from participant evidence, which indicated that the initiative promoted an opportunity to try a new skill, outside of their home environment, with limited help. This was something they would not ordinarily consider doing for a variety of reasons, including confidence and safety (Mayo et al., 2015). As Andrew commented:

I have felt better yeah because today I'm doing this ... you see people, you go round everyone, and then you meet people, more and more ... then the next thing is Monday, then everyone's gone. What am I doing? I can't do nothing. So do this and that in the house, and get fed up with it ... If I'm on my own there's no one to talk to .. You want to talk to someone but none [there].

This sentiment is also evidenced by Brian, who said that the initiative was "better rather than sitting at home or doing nothing yeah, yeah" adding that "you can socialise more and if you are tired you can have a chat". Similarly, Catherine suggested that "if I wasn't doing this I'd be at home. I wouldn't go out. So it's like getting you out, yeah... you are all in the same boat for one reason or another". Returning to the Jackie, it was also argued that the "social side [is] very important ... the benefits are more mental health related". Sports development officer Fred, who had experience delivering disability golf sessions, explained in more detail the important role "personal satisfaction" plays in this regard, adding that:

It's the 'I can do attitude' ... it's that you've give it a go ... that personal satisfaction and a reward built in for achieving together with others ... you listen, you try, and achieve 

... the attitude is generally [in wider society] that you [people with disabilities] can't do that and you can't do this, but it generates a good feeling when they can.

It appears, therefore, that creating an environment of independence is a key part of encouraging people with physical limitations to play golf. At the same, however, it is important that such sessions are delivered in such a way that they are not differentiated too much from 'regular' golf and include integration wherever possible. Returning to Fred, who argued that "if it's differentiated too much, however, then are they really doing something comparable? Is the activity being cheapened and are they being judged?" as participants "do not want to be defined by an impairment but rather measure themselves amongst everybody else".

Benefits in terms of physical health were also cited by participants in this study. It was commented that the 'get-into-golf' initiative proved important to develop flexibility (via stretching), strength (via hitting golf shots), and thus helped increase confidence given the effect on their overall physical abilities. When asked about the benefits and rationale for taking part, Catherine said "I found it very good for the exercise ... to improve flexibility and confidence really ... the exercise does help to strengthen your weak side so just carry on with the exercises". Similarly, Brian identified that "the stretching, in particular at the start of the session, was useful to help with mobility". Finally, Catherine rather clearly stated that "it really does keep you fit. I have noticed the difference, yeah. So I am more and more mobile, I do more stuff, you know". Grace, a coach with experience delivering disability sessions, drew on a comparison between the physical aspects of golf and how this may promote independence. Grace acknowledged that it is "difficult to generalise and there's a such a huge spectrum" but: Generally speaking, golf is fairly low impact, do it at whatever level you like, from range to course and it is informal if taught in right surroundings ... it's also inclusive 
where a lot of people with disabilities can slot into sessions with people who may or may not have a disability ... golf is a great leveller in that respect.

It should be noted, however, that taking part in the initiative was not an easy process for the stroke survivors, and many actually found it physically demanding, with some of the main challenges relating to their balance and coordination. These physiological reasons have been cited as a reason that survivors may look stay indoors post-stroke (Mayo et al., 2015; Nicholson et al., 2013; Sacco et al., 2006), whereas the 'get-into-golf' programme provided an opportunity to exercise in a supportive environment with other people in similar situations. The coaches involved in this initiative, including Harry, identified the importance of "including warm up exercises and stretching" while also "slowly progressing onto fuller shots". Deborah commented on the benefits of the programme, by saying "I am doing exercise that I didn't do before so that's healthier. I'm outside in the fresh air". When asked if they feel better, physically, after taking part in the initiative, Deborah responded "yes I do", adding "I don't know why, but when I get home my husband notices. He knows I've been out and had a good time. He just says I'm more lively, yeah". This corroborates with the focus group data, where Irene commented that a "client wanted to Get-into-Golf had lost his confidence ... and this programme helped that". Irene continued to say that the initiative helped improve overall confidence and levels of well-being by "learning a skill, building confidence, and improving skill, all while meeting others not in clinical environment".

\section{Supporting Stroke Survivors Playing Golf}

So far this paper has outlined some of the positive effects associated with playing golf from the point of view of people who have survived a stroke. It did, however, become clear that there were a number of barriers to participation, with interviewees also highlighting various ways to reduce the effect of such issues in future programmes. The notion of trying to 
1 support independence amongst stroke survivors, in regards to undertaking basic activities on

2 their own, has been highlighted as a key part in the overall process of rehabilitation (Mayo et

3 al., 2015). That is, stroke survivors often struggle to undertake everyday activities without

4 support, which they could before having a stroke, so making adaptations to the golf

5 environment and ensuring spaces are adequately organised to promote independence was

6 clearly very important. As Deborah highlights, "the exercise bit is difficult, but you get through

7 it and feel good after you done it. You get a bit tired and that's about it". The power tees, for

8 example, which automatically raise the ball without the need for bending down were cited as

9 being advantageous. During the focus group, Jackie revealed that the "driving range worked

10 well" where "clients could work in pairs" and thus splitting the amount of time spent actually

11 hitting golf balls. It was also cited that "chairs to sit down [were] useful, [due to] balance problems do not want to stand up all the time”. Such sentiments are support by participant data, including Catherine, who described some of the difficulties by saying that "you can't move, you can't balance. Walking sometimes is an issue". At the same time, it is important to appreciate that these supportive elements should be viewed as an integral part of the golf environment, and not 'just' for the stroke survivors in order to ensure they are "not made to feel different" and thus further contributing to feelings of independence.

The importance of considering novel approaches to help reduce amount of time spent on an intensive activity was viewed as extremely important. In this regard, considerations should also be made to the order and location in which the activities are structured. This might begin with putting before gradually moving onto the driving range and course elements. As Edward, a golf coach with experience of teaching people with disabilities, argued that considerations should be made to "promoting putting to generate early achievement" adding that the "reality of getting on the golf course itself can be tricky". It does, of course, depend on 
1 the specific nature of the individuals involved. As Edward was keen to state, sessions should

2 be "personalised and needs led ... where a 'pre' conversation with customer has taken place

3 before to get a better understanding of what is required ... to make the session more suited to

4 their needs". It should also be stated that the issue of independence largely relies on the golf

5 clubs' / professionals' knowledge about stroke limitations. As Brian states, "he [the pro]

6 understood well the limitations of what you can and can't do". Similarly, Catherine commented

7 that "he [the pro] was good very good, and the student that was with him last week was

8 excellent". Indeed, the coaching staff involved in the programme under analysis here were

9 particularly commended, however, it was also noted that more involvement of golf personnel

10 in Stroke Association meetings, for example, would help raise awareness even further. This,

11 according to Irene during the focus group, it would also be useful from policy point of view, given that stroke survivors "tend to have some coordination issues, so there are some health and safety and danger issues [to consider]".

When considering the format of golf sessions for people who had survived a stroke, there was a consensus that one hour in duration, scheduled for one day per week, over a six week period was appropriate. As Brian highlighted "they work it nicely, one hour, one hour of practice that's enough" adding that "6 weeks and that is enough". Catherine reiterates this by saying "yeah it's good, an hour is enough because a lot of us get tired after an hour or so. It wouldn't be any use longer I don't think". There are, of course, individual differences in the nature and severity of physical disability post-stroke (Sacco et al., 2006), but the perception from this sample was that anything longer than this might have proved difficult to participate in. Participants were keen to highlight the important impact financial cost made on their decisions to take part activities. Many stroke survivors are not in full employment and may, therefore, struggle to meet any restrictive costs associated with golf initiatives, such as 
1 expensive club membership and equipment (Nicholson et al., 2013; Piggott, Leslie, \& Poller,

2 2011; Rand et al., 2010; Simpson \& Eng, 2011). The cost of the 'Get-into-Golf' programme under analysis in this paper was shared between the participants and the Stroke Association, which was identified as a positive by the participants. This was specifically highlighted by Brian, who said "half of the cost was from the Stroke Association, that was very good" and Deborah raised the important point that "at the minute, [the equipment is] provided. It's expensive, it's very expensive". The cost of equipment has been regularly cited as barrier in golf participation amongst general populations (Piggott, Leslie, \& Poller, 2011), but this issue is, arguably, even more relevant for stroke survivors who may require specially adapted clubs and accessories. The golf clubs involved in this particular programme were commended for offering a large selection of clubs, so that each participant could try a variety and see identify which is best for them. As Brian identified, "the pro has a selection of different items ... they can change one or two or three of the irons, yeah". There are various pieces of equipment to help people with disabilities play golf, from specialized gloves to prosthetic attachments, in addition to teaching resources aimed to help execute a golf swing one way or another, whether from a seated position, or using just one arm to swing (Sandt, Flynn, \& Turner, 2014; Stoter et al., 2017; Wood, Henrikson, \& Lewis, 2016). This is not, of course, to suggest that all equipment adaptations have a large cost associated with them. Indeed, there were a number of simple things discussed the with Jackie in the focus group including that "yellow balls can be easier to see" and "lighter clubs would be useful", due to coordination and strength limitations which are common post-stroke (Sacco et al., 2006; Sandt, Flynn, \& Turner, 2014; Wood, Henrikson, \& Lewis, 2016). Furthermore, it is also important to highlight that considering the cost of playing golf does not, necessarily, mean lowering the price of regular membership/green fees for people with disabilities. As Fred, a sports development officer who has worked on creating national disability initiatives, was keen to state there is a need to "move beyond the 
1 perception that everything must be funded and every session must be free, rather trying to

2 promote independence". It was suggested, instead, that there could be more pay and play options, flexible memberships (such as points and 'lifestyle' based), and offerings of non traditional versions of golf (such as adventure golf and short courses) at different price points "where it fits as part of the club's business plan" (Fred). This sentiment is also supported by Edward, who argued that a "lot of people with disabilities do not want it [playing golf] any cheaper ... they have jobs and whatever ... but don't want disability membership and wish to be treated as an equal ... so it might be having a flexi membership, but it's available for everybody, such as a twilight membership".

Closely linked with cost is the issue of access and transport (Nicholson et al., 2013; Rand et al., 2010). Participants in this study identified that good transport links is an important factor in their decision to take part, with many stroke survivors not being able to drive and thus only being able to attend should they be able to get taken (Nicholson et al., 2013). As Andrew clearly states, "in all honesty the only problem is getting people to help me to get here ... if you live far away, it's trying to get here is hard [sic]. Erm, at the moment I'm lucky as my daughter comes here, so that's fine. But other times just couldn't do it". Catherine also highlights the important point that "golf courses aren't normally on bus routes or anything, so transport can be a problem" adding that "a lot of people have people to come and pick them up, but some of us haven't". Golf coach Edward supported this point by saying "transportation and finance is one of the biggest issues ... to get themselves here in the first place". The maximum distance participants were happy to travel was around 30 minutes and car sharing or taking the bus was specifically identified as a way to help minimise this issue. Similarly, awareness of the programme was cited as an important area for improvement, with the perception amongst participants that many stroke patients do not know that these sessions, firstly, actually exist, 
1 and, secondly, that they are structured in such as a way that stroke survivors are able to take

2 part. There was an overwhelming view that if more stroke survivors were aware about the initiative, they would try it and enjoy it. As Brian states, "some of [the] people in group didn't know about golf session, and what it is doing [sic], and they must tell them to come and see". This was, however, framed with caveat that the success of these types of golf initiatives are very much weather dependent. That is, given sessions delivered in an outdoor environment, and this particular programme was during the winter months, this could very much impact on any physical conditions amongst a group of people who already have decreased mobility post stroke. As Brian rather bluntly noted, "if the weather is really bad then you can't [play]".

\section{Conclusions}

The central objective of this paper was to assess the barriers and facilitators to golf participation amongst people who have experienced a disability from a stroke. In particular, it sought to identify stroke survivors' perceptions of a five week 'Get-into-Golf' programme, including what they found difficult about participation and ways to reduce the effect of such issues. There was an overwhelmingly positive response from participants regarding their experiences of the get-into-golf programme. It is argued that the 'social elements' of this type of initiative, such as meeting new people in a similar scenario to themselves, are a particular strength. At the same time, the opportunities for such initiatives to promote independence was also cited as a positive. That is, participants spoke highly about the opportunity to try a new skill outside of their home environment with limited help, something which had been difficult post-stroke for reasons such as confidence and safety. Benefits in terms of physical health were also revealed by participants, such improving strength and flexibility, and the associated impacts this can have on their overall physical abilities and confidence levels. There was a strong feeling of the 
1 benefits of such sports programmes health and well-being amongst stroke survivors, but this is

2 not to suggest participation was without its problems. Indeed, this paper has also highlighted

3 that considerations in regards to independence, format, equipment, cost, access and overall

4 awareness should be borne in mind when considering disability golf participation at golf clubs,

5 many of which, it would seem, still have opportunities for improvement. We return to Grace,

6 who argues that "sometimes clubs aren't set up for disabilities, they are not disability friendly

$7 \quad$... we are a very poor! Gosh, honestly, have they got the right number of disabled parking spaces? Or steps to clubhouse? Or a hearing loop? If you started looking at how many clubs fit that criteria then it would be surprisingly low ... I think less than $30 \%$, and that's being optimistic, are set up to accommodate a disabled person .... this is particularly worrying given the aging representation of members in our golf clubs". It is in these areas that we suggest a preliminary framework in which golf clubs could employ in order to help aid participation amongst people who have physical limitations. Considerations should be made to:

- Independence: ways in which independence can be promoted through participation in golf. This could be, for example, strategic location of location of, and distance between, bathroom / rest facilities on course and around clubhouse areas, automatic tees on driving ranges, and considerations around use of adaptive golf carts.

- Format: the order and location that the golf activities are structured. Physical disability impacts on duration and amount of golf that can be played, so considered use of alternative playing formats (e.g. scrambles), driving range sessions working in pairs, social games, and amended course lengths is important. A confidential confidence rating could assess the most appropriate way to organise golfing tasks, and help ensure adequate levels of health and safety. This may also include individualised golf instruction offering alternative activities suitable for people with various levels of 
readiness. For example, visual cues and coloured bands can be used to prompt foot placement or guide hand placement.

- Equipment: equipment modifications designed to help make golf more accessible. This may include readymade access to 'traditional' golf clubs but of various materials (e.g. regular metals, graphite, or plastic), weights (e.g., light, regulation), angles (e.g. low lie, regulation), and lengths (e.g. longer shaft), in addition to bespoke equipment designed especially for people with physical limitations, such as 'chair' putters, 'zero swing' clubs, and Velcro golf gloves.

- Cost, access, and awareness: ways to keep down costs for groups that may not be in full time employment. This is particularly important given the restrictive costs of specially adapted equipment. Closely linked is transport, where it is increasingly important to promote initiatives around golf club locality. In this study, participants were happy to travel around 30 minutes. Awareness of issues surrounding disabilities, such as modified rules and equipment, could be promoted in the golf club through training personnel.

This paper supports previous research, with appreciation of the benefits of golf and physical activity for stroke survivors (Pollock, et al., 2014; Rimmer, Wang, \& Smith, 2008; Saunders et al., 2016; Schachten \& Petra, 2015). The present study also adds to these findings by indicating the potential barriers and facilitators to lifelong participation in golf. This said, it should be highlighted, however, that this study is limited by the small number of participants, all of which were clearly open to the idea of the benefits of sport and physical activity on their health given they originally opted to take part in the initiative. Future research could focus on 
1 the views and experiences of stroke survivors who do not wish to take part in physical activity

2 to attempt to understand why. The practical insights offered here can help build guidelines for

3 golf clubs aiming to increase participation amongst groups of people with various levels of

4 disability. Furthermore, such research may be used to inform industry policy and, even, aid

5 towards producing a service quality certification mark for golf clubs that identifies and

6 promotes safe and accessible facilities, as part of the overall England Golf 'GolfMark'

7 accreditation. The current handicap system, for example, does not take into account the

8 possible challenges of playing golf with any form of physical disability. As such, Kenny et al.

9 (2015) argue that disabled golfers are currently penalised / disadvantaged by the handicap

10 classification rules as it does not take into consideration either the possible unique challenges

11 of playing golf with any form of disability, or the potential effects of a disability on

12 performance. It is argued that opportunities to promote golf as a lifelong physical activity

13 among people with disabilities may be missed in clubs where personnel are unsure of the

14 barriers and facilitators to participation outlined here.

16 Acknowledgements

17 The research team would like to thank the participants who gave their time to be part of this 18 study. 


\section{References}

American Heart/Stroke Association (AHSA, 2016). Saving Strokes - golf clinic for Stroke survivors. Retrieved from:

http://scvmcrehab.org/upload/userfiles/American\%20HeartStroke.pdf

Bryman, A. (2015). Social research methods. (5th Ed.). Oxford: Oxford University Press.

Chen, C., Leys, D., \& Esquenazi, A. (2013). The interaction between neuropsychological and motor deficits in patients after stroke. Neurology, 80 (2), 27-S34.

Egan, M., Davis, C.G., Dubouloz, C.J., Kessler, D., \& Kubina, L.A. (2014). Participation and well-being poststroke: evidence of reciprocal effects. Archives of Physical Medicine and Rehabilitation, 95(2), 262-268.

England Golf. (2016). Stroke survivors tee off in Crewe. Retrieved from: https://getintogolf.org/news-room/stroke-survivors-tee-off-increwe? returnlink=http $\% 3 \mathrm{~A} \% 2 \mathrm{~F} \% 2 \mathrm{Fgetintogolf}$. org $\% 3 \mathrm{~A} 8080 \% 2 \mathrm{Fnews}$.aspx $\% 3 \mathrm{Fsites}$ ectionid\%3D208\%26originalpath\%3Dnews-room\%252Fstroke-survivors-tee-off-increwe\%26range\%3DLatest.

Guest, G., Bunce, A., \& Johnson, L. (2006). How many interviews are enough? An experiment with data saturation and variability. Field Methods. 18(1), 59-82.

Hackett, M.L., \& Pickles, K. (2014). Part I: frequency of depression after stroke: an updated systematic review and meta-analysis of observational studies. International Journal of Stroke, 9(8), 1017-1025.

Johnston, S.C., Mendis, S., \& Mathers, C.D. (2009). Global variation in stroke burden and mortality: Estimates from monitoring, surveillance, and modelling. The Lancet, 8, 345354.

Jones, I. (2014). Research methods for sports studies ( $3^{\text {rd }}$ Ed.). London: Routledge.

Kenny I.C., Campbell, M.J., Surmon, S., \& Bressan, L. (2015). Drive performance for ablebodied and disabled golfers. International Journal of Sports Science \& Coaching, 10(4), 757-767.

Korner-Bitensky, N., Desrosiers, J., \& Rochette. A. (2008). A national survey of occupational therapists' practices related to participation post-stroke. Journal of Rehabilitation Medicine, 40(4), 291-297.

Marzolini, S., Oh, P., McIlroy, W., \& Brooks, D. (2013). The effects of an aerobic and resistance exercise training program on cognition following stroke. Neurorehabilitation and Neural Repair, 27, 392-402.

Mayo, N., Anderson, S., Barclay, R., Cameron, J.I., Desrosiers, J., Eng, J.J., Huijbregts, M., Kagan, A., Lyons, M.M., \& Moriello, C. (2015). Getting on with the rest of your life following stroke: A randomized trial of a complex intervention aimed at enhancing life participation post stroke. Clinical Rehabilitation. 29:1198-211. 
Nicholson, S., Sniehotta, F.F., van Wijck, F., Greig, C.A., Johnston, M., McMurdo, M.E.T., Dennis, M., \& Mead, G.E. (2013). A systematic review of perceived barriers and motivators to physical activity after stroke. International Journal of Stroke. 8:357-64.

O'Sullivan, C. \& Chard, G. (2010). An exploration of participation in leisure activities poststroke. Australian Occupational Therapy Journal. 57:159-66.

Piggott, D., Leslie, G., \& Poller, G. (2011). Widening participation in golf: Barriers to participation and golfmark. School of Sport, Coaching and Exercise Science Research Group, University of Lincoln.

Pollock, A., Baer, G., Campbell, P., Choo, P.L., Forster, A., Morris, J., Pomeroy, V.M., \& Langhorne, P. (2014). Physical Rehabilitation Approaches for the Recovery of Function and Mobility After Stroke. Stroke. 45:e202.

van de Port, I.G.L., Wevers, L.E.G., Lindeman, E., \& Kwakkel, G. (2012). Effects of circuit training as alternative to usual physiotherapy after stroke: Randomised controlled trial. BMJ (Clinical Research ed.), 344, e2672.

Veal, A.J. \& Darcy, S. (2014). Research methods in sport studies and sport management: A practical guide. London: Routledge.

Rand, D., Eng, J.J., Tang, P.F., Hung, C., \& Jeng, J.S. (2010). Daily physical activity and its contribution to the health-related quality of life of ambulatory individuals with chronic stroke. Health and quality of life outcomes. 80.

Rimmer, J.H., Wang, E., \& Smith, D. (2008). Barriers associated with exercise and community access for individuals with stroke. Journal of Rehabilitation Research and Development. 45:315-22.

Rubin, H.J. (2011). Qualitative interviewing: The art of hearing data. UK: Sage Publications, Inc.

Sacco, R.L., Adams, R., Albers, G., Alberts, M.J., Benavente, O., Furie, K., Goldstein, L.B., Gorelick, P., Halperin, J., \& Harbaugh, R.. (2006). Guidelines for Prevention of Stroke in Patients With Ischemic Stroke or Transient Ischemic Attack A Statement for Healthcare Professionals From the American Heart Association/American Stroke Association Council on Stroke: Co-Sponsored by the Council on Cardiovascular Radiology and Intervention: The American Academy of Neurology affirms the value of this guideline. Circulation. 113:e409-e49.

Sandt, D.D., Flynn, E., \& Turner, T.A. (2014). Promoting golf as a lifetime physical activity for persons with disabilities. Strategies, 27(1), 18-25.

Saunders, D.H., Sanderson M., Hayes, S., Kilrane, M., Greig, C.A., Brazzelli, M., \& Mead, G.E.. (2016). Physical fitness training for stroke patients. Cochrane Database of Systematic Reviews. 3.

Schachten, T., \& Petra, J. (2015). The effects of golf training in patients with stroke: A pilot 
study. International Psychogeriatrics, 27(5), 865-873.

Shatil, S., Ivanova, T.D., Mochizuki, G., \& Garland, S.J. (2005). Effects of therapeutic golf rehabilitation on golf performance, balance, and quality of life in individuals following stroke: pilot study. Physiotherapy Canada, 57, 101-112.

Simpson, L.A., Eng, J.J., \& Tawashy, A.E. (2011). Exercise perceptions among people with stroke: Barriers and facilitators to participation. International journal of therapy and rehabilitation. 18:520-30.

Stoter, I.K., Hettinga, F.J., Altmann, V., Eisma, W., Arendzen, H., Bennett, T. van der Woude, L.H, \& Dekker, R. (2017). Initial steps towards an evidence-based classification system for golfers with a physical impairment. Disability and Rehabilitation, 39(2), 152-163.

Wood, P., Henrikson, E., \& Lewis, J. (2016). A novel method to grip a golf club for a quadruple amputee golfer. Sports Engineering, 19, 171-176.

Figure 1 Barriers and facilitators of disability golf participation

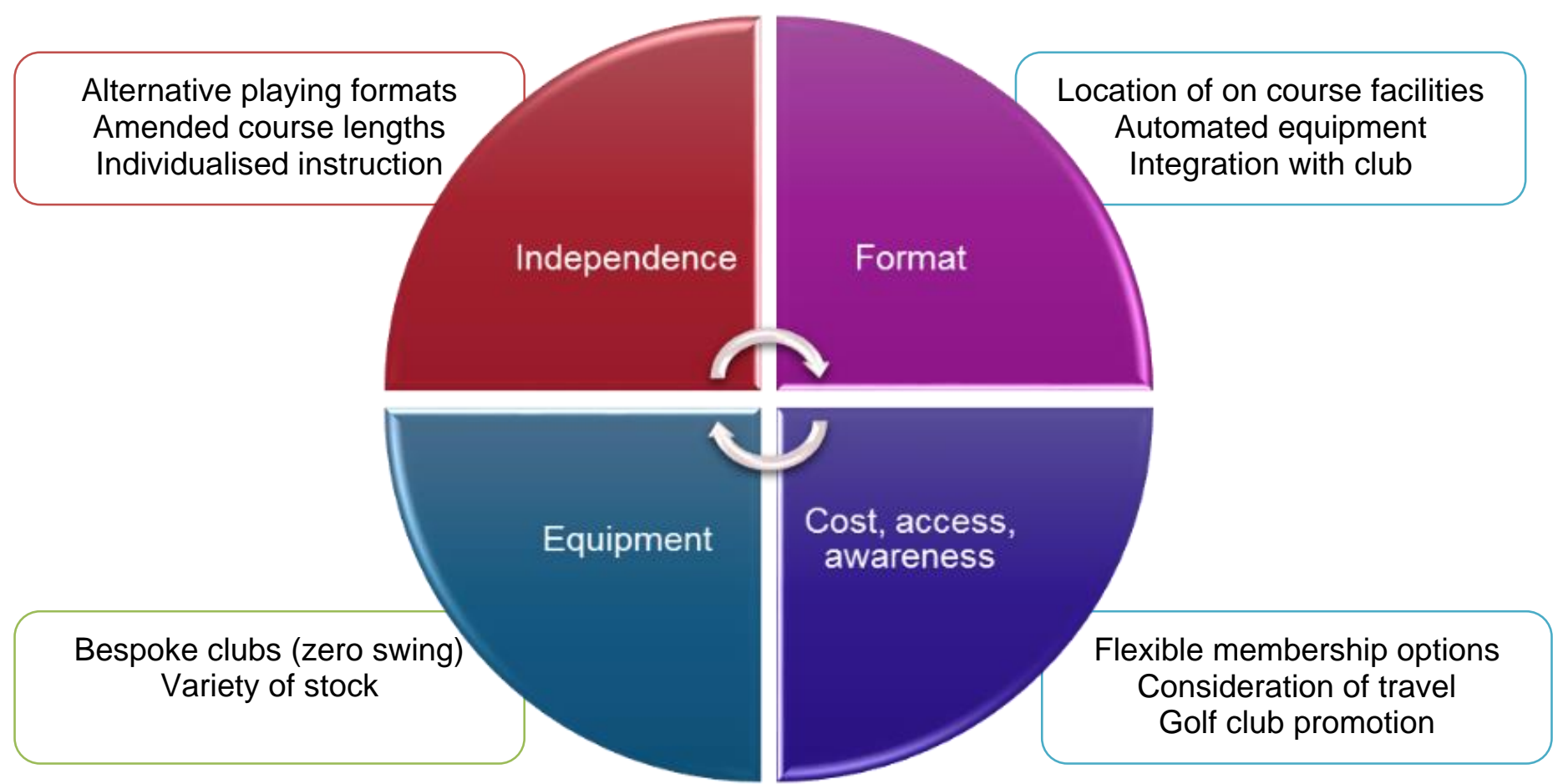

